УДК 614.876-616-097

\title{
ВЛИЯНИЕ РАДИАЦИОННОГО ИЗЛУЧЕНИЯ НА ИММУННУЮ СИСТЕМУ (ОБЗОР ЛИТЕРАТУРЫ)
}

1Узбеков Д.Е., ${ }^{1}$ Кайрханова Ы.О., ${ }^{2}$ Хоши М.М., ${ }^{1}$ Шабдарбаева Д.М., ${ }^{1}$ Саякенов Н.Б., ${ }^{1}$ Апбасова С.А., ${ }^{1}$ Толегенов М.М., ${ }^{1}$ Рахыпбеков Т.К.

${ }^{1}$ Государственный медицинский университет, Семей, е-таil: Med.lib.53@таil.ru; ${ }^{2}$ Медицинский университет, Шимане, е-таil: mhoshi@hiroshima-u.ac.jp

\begin{abstract}
Несмотря на многочисленные научные исследования влияния радиационного излучения на иммунную систему, возникла необходимость вновь вернуться к данной проблеме. Как известно, хроническое воздействие в малых дозах ионизирующего облучения в первую очередь действует на Т-систему иммунитета, что способствует возникновению развития аутоиммунных процессов. Литературные данные свидетельствуют о неблагоприятном влиянии ионизирующего излучения на состояние здоровья жителей пострадавших регионов, подвергшихся воздействию испытаний ядерного оружия. Следовательно, высокая радиочувствительность иммунной системы, а также стойкость во времени и даже необратимость некоторых пострадиационных изменений иммунитета способствуют развитию отдаленных последствий облучения, основным клиническим проявлением которого являются различные формы иммунодефицита. Результаты анализа супрессирующего действия радиации на иммунную систему показали, что иммунодепрессия определяется нарушением клеточных функций. Исследование характера иммунных расстройств при разных уровнях и типах радиационного воздействия позволит использовать результаты исследования для прогноза отдаленных последствий пролонгированного облучения.
\end{abstract}

Ключевые слова: радиация, иммунная система, лимфоциты

\section{INFLUENCE OF RADIATION ON THE IMMUNE SYSTEM (LITERATURE REVIEW) ${ }^{1}$ Uzbekov D.E., ${ }^{1}$ Kairkhanova Y.O., ${ }^{2}$ Hoshi M.M., ${ }^{1}$ Chaizhunusova N.G., ${ }^{1}$ Shabdarbaeva D.M., ${ }^{1}$ Sayakenov N.B., ${ }^{1}$ Apbasova S.A., ${ }^{1}$ Tolegenov M.M., ${ }^{1}$ Rakhypbekov T.K. \\ ${ }^{1}$ The State Medical University, Semey,e-mail: Med.lib.53@mail.ru; ${ }^{2}$ Shimane Medical University, Shimane,e-mail:mhoshi@hiroshima-u.ac.jp}

\begin{abstract}
Despite numerous research of radiation effects on the immune system, there was a need come back to this problem again. As is known, chronic exposure in low doses of ionizing radiation primarily influence on the Timmune system, which contributes to the development of autoimmune processes. Published data suggest about adverse effects of ionizing radiation on residents health of the affected regions exposed to the testing of nuclear weapon. Consequently, the high radiosensitivity of the immune system, as well as resistance over time and even irreversible of changes of some post-radiation immunity contributes to long-term radiation effects, the main clinical manifestations are different immunodeficiencies. The analysis results of suppressing radiation effects on the immune system have shown that immunodepression state determined by the disorders of cellular functions. The nature research of immune disorders during different levels and types of radiation effect will allow the use of research results for the prediction of long-term effects of prolonged exposure.
\end{abstract}

Keywords: radiation, immune system, lymphocytes

Возникающие в организме патологические процессы как в ответ на радиационное воздействие вовлекают различные системы и органы человека опосредованно через иммунную систему [28, 31, 43], обладающую высокой радиочувствительностью [24]. Особенностью ионизирующего излучения является долговременное сохранение дефектов в отдельных звеньях системы иммунитета и как следствие возникновение осложнений [1]. Представляется оценить вклад радиационного фактора в изменение показателей иммунной системы и его связь с развитием патологических синдромов $[6,48]$.

Реакция иммунной системы на радиационное воздействие зависит от дозы, времени, мощности, а также от качества облучения [32, 37, 38, 40, 41]. Известно, что регулярная зависимость эффекта от величины дозы радиации встречается в диапазоне доз 1-7 Гр [3]. В настоящее время разработана математическая модель для расчета распределения поглощенной энергии вокруг источников гамма-излучения во внутренних органах как в эксперименте, так и у человека [23]. За последние годы проведен целый объем научных исследований, направленных на оценку рисков стохастических эффектов в разных дозах облучения [34, 44, 46]. Малые дозы способствуют активизации иммунной системы у разных видов животных [16]. И как следствие, в свете актуальных представлений о значении иммунной системы в регуляции процессов жизнеобеспечения и универсально «возмущающихся» факторов для си- 
стемы иммуногенеза закономерно мнение о нацеленной иммунологической перестройке облучённого малыми дозами организма, приводящей к созданию противорадиационного иммунитета [17]. Эффекты динамики лимфоцитов через сутки после $\gamma$-облучения малыми дозами является процессом изменчивым, мгновенно реагирующим и сохраняющим постоянство в продолжительности наблюдения через год повышением числа стромальной и интраэпителиальной клеточной популяции [5]. Известно, что у лиц, подвергшихся лучевой терапии могут возникнуть повреждения иммунной системы организма. Последствия лучевой терапии высокими дозами сказываются раньше, чем те, которые обусловлены воздействием низких доз. Часть лимфоцитов после воздействия высокими дозами может погибнуть в течение двух дней, делая организм чувствительным к разнообразным инфекциям [25]. Было установлено, что изменение иммунологических реакций, усиление аутоиммунных процессов возникает в результате гипоплазии лимфатических узлов [45]. Следует отметить, что тяжесть лучевых поражений определяется скоростью обновления и радиочувствительностью клеток [19]. Повышение чувствительности к радиационному воздействию и нарушение индукции адаптивного ответа в клетках является проявлением нестабильности генома [7, 9]. Изучение изменения частоты клеток с микроядрами в зависимости от дозы облучения красного костного мозга является важным показателем, отражающим уровень радиационного повреждения стволовых кроветворных клеток [42].

Материалы многолетних медицинских исследований, проведенных среди лиц, проживающих в районах Семипалатинской области, расположенных в зонах радиационного риска, позволили установить основные уязвимые системы облученного организма, среди которых особый интерес придается генетическому аппарату и иммунной системе [10]. Так, рассматривая цитокины как важнейший фактор формируемых иммунологических реакций, А.А. Ярилин и соавторы уделяли большое внимание цитокинам в становлении иммунологических систем, в частности Т-системы лимфоцитов [22]. У жителей всех обследованных населенных пунктов, подвергшихся радиационному воздействию, выявленные изменения в субпопуляционной структуре и функциональных свойствах иммунокомпетентных клеток и уровне цитокинов лежат в основе регистрируемого роста частоты встречаемости различных иммунопатологических синдромов, что ука- зывает о серьезных изменениях в иммунной системе [18]. Контингент ликвидаторов последствий аварии на ЧАЭС представляет удобную модель для исследования соматического мутагенеза в отдаленные сроки после радиационного воздействия [20]. Немаловажное значение приобрел тот факт, что у ликвидаторов отмечается повышение частоты хромосомных аббераций в лимфоцитах периферической крови [27, 29, 35]. На основании результатов исследований проведённых на ядерном предприятии производственное объединение «Маяк» было установлено существенное снижение содержания Т-лимфоцитов и Т-хелперов с увеличением дозы облучения [15]. Результаты проведённой работы сопоставляются с работами изученными ранее у жителей Хиросимы и Нагасаки, выживших после атомной бомбардировки [33], для которых радиационный фон был доминантным за счет нейтронной активации [26]. Одним из доминирующих нейтрон-активированных радионуклидов стал ${ }^{56} \mathrm{Mn}[36,47]$. Этиологическую роль ионизирующего излучения среди переживших в 1945 году атомные взрывы, в Хиросиме и Нагасаки, подтвердил анализ частоты острых лейкозов, хронических миелолейкозов и нестабильности геномного аппарата [39].

Исследования влияния ионизирующего излучения на живые организмы тесно связано с оценкой состояния деятельности регуляторных сетей, координирующих системные ответы на лучевое воздействие [12]. Первостепенным срединихявляется апоптоз, преобладающий в популяции иммунокомпетентных клеток лимфоидных органов, что обусловливает актуальность исследования расстройств иммунной системы на уровне функциональных свойств иммунокомпетентных клеток [2]. Существенными являются обобщающие работы А.А. Ярилина и соавторов по механизмам развития апоптотической гибели клеток и механизмам формирования внутриклеточных сигнальных путей, индуцирующих ответные реакции клеток на различные воздействия внешних факторов [30]. У экспериментальных животных, подвергавшихся пыле-радиационному фактору, в отдаленном периоде выявлены значительные изменения, проявляющиеся снижением количества лейкоцитов, абсолютного и процентного количества $\mathrm{CD} 3+, \mathrm{CD} 4+, \mathrm{CD} 8+$, уровня ЦИК и иммуноглобулинов различных групп, а также снижением функциональной активности нейтрофилов [8]. Дозозависимое формирование иммуносупрессии характеризуется абсолютной Т-лимфо- 
пенией с преимущественным угнетением CD4+-клеток и активности фагоцитоза, угнетением функциональной активности естественных киллеров (NK) со снижением их количества, повреждением основной функции иммунной системы, т.е. контроля за генетическим постоянством клеточного состава с воплощением в канцерогенный эффект [14]. Индуцированная радиацией иммуносупрессия способствует развитию синдромов иммунологической недостаточности, которая ведет к увеличению стохастических эффектов [4]. Изучение состояния иммунного статуса у потомков облученных белых крыс показало, что иммунологические нарушения обусловлены повышением содержания В-лимфоцитов, снижением количества субпопуляций общих Т-лимфоцитов, лимфоцитов с хелперной активностью и иммунорегуляторного индекса [11].

Таким образом, несмотря на имеющиеся данные об изменениях обменных процессов в иммунокомпетентных органах у потомков лиц, подвергнутых малым дозам ионизирующей радиации [21], изучение отдаленных последствий различных дозовых нагрузок гамма-излучения на иммунную систему организма остается актуальной проблемой медицины и радиобиологии [13]. Особый интерес представляет проведение сравнительной характеристики морфологических и физиологических изменений в органах иммунной системы у поколений лиц, подвергавшихся действию гамма- и нейтронного излучения, позволяющая выявить информативные критерии оценки влияния радиационного фактора в зависимости от накопленной дозы.

\section{Список литературы}

1. Аклеев А.В., Шалагинов С.А. Опыт экспертизы состояния здоровья граждан, подвергшихся радиационному воздействию// Медицинская радиология и радиационная безопасность. - 2011. - Том 56, № 1. - С.11-17.

2. Андрийчук Т.Р., Ракша Н.Г., Луговая С.Л., Мандрык С.Я., Остапченко Л.И. Влияние ионизирующей радиации на индукцию и реализацию программированной клеточной гибели // Биологические эффекты малых доз ионизирующей радиации и радиоактивное загрязнение среды. Меж. конф. Сыктывкар, 2014. - С. 11-14.

3. Асадуллина Н.Р., Гудков С.В., Брусков В.И. Антиоксидантные свойства ксантозина при воздействии рентгеновского излучения // Фундаментальные исследования. 2011. - № 10-1. - С. 22-25.

4. Белозеров Е.С., Киселева Л.М., Макаров М.А., Игнатьев С.Б. Индуцированные радиацией факторы, определяющие высокую инфекционную заболеваемость // Сибирский медицинский журнал. - 2008. - № 7. - С.117-120.

5. Воронцова 3.А., Зюзина В.В. Иммунные эффекты на воздействие малых доз $\gamma$-облучения в эксперименте // Фундаментальные и прикладные исследования в медицине. Материалы конференции (Франция, Париж, 15-22 октября 2011 г.). - 2011. - № 11. - С. 80-81.
6. Загуменнова О.Н., Малышева Е.В., Гулин А.В. Исследование субпопуляции лимфоцитов людей, подвергшихся хроническому радиационному воздействию // Журнал Вестник Тамбовского университета. Серия: Естественные и технические науки. - 2013. - Том 18, № 5-3. - С. 2877-2881.

7. Засухина Г.Д. Адаптивный ответ - общебиологическая закономерность: факты, гипотезы, вопросы [Текст]/ Г.Д. Засухина // Радиационная биология. Радиоэкология. 2008. - Т. 48. - № 4. - С. 464-473.

8. Ильдербаев О.3. Влияние фитопрепарата Be betula pendula roth на иммунологическую реактивность организма подвергавшегося к сочетанному воздействию радиации 6 Гр и асбестовой пыли в отдаленном периоде // Фундаментальные исследования. - 2008. - № 8. - С. 112-114.

9. Ингель Ф.И. Перспективы использования микроядерного теста на лимфоцитах крови человека, культивируемых в условиях цитокинетического блока [Текст] /Ф.И. Ингель // Экологическая генетика. - 2006. - Т. 4. - №3. - С. 7-19.

10. Корсаков А.В. Многофакторное техногенное загрязнение окружающей среды как фактор риска формирования цитогенетических нарушений у населения // Вестник Брянского государственного технического университета. 2014. - № 2. - C. 155-160.

11. Мадиева М.Р, Узбеков Д.Е., Терликбаева Г.А., Ильдербаев О.З. Некоторые иммунологические показатели у потомков облученных животных // Международный журнал прикладных и фундаментальных исследований. - 2012. №1. -32 c.

12. Мазурик В.К. Роль регуляторных сетей ответа клеток на повреждения в формировании радиационных эффектов // Радиационная биология. Радиоэкология. - 2005. T. 45. № 1. - C. 26-45.

13. Матюшонок Н.С., Князев В.С. Биологическое действие гамма-излучения // Успехи современного естествознания. - 2011. - № 8. - 120 c.

14. Русскова А.Н. Новые сведения об иммунносупрессии // Международный журнал экспериментального образования. - 2010. - № 8. - С. 47-49.

15. Рыбкина В.Л., Азизова Т.В., Майнеке В., Шертан Г., Дёрр Х., Адамова Г.В., Теплякова О.В. и др. Влияние хронического облучения на некоторые показатели иммунитета // Иммунология. - 2015. № 36 (2). - С. 145-149.

16. Сафонова В.Ю., Сафонова В.А. Биологическое влияние малых доз радиации, аспекты безопасности // Известия Оренбургского государственного аграрного университета. 2011. - Том 3, № 31-1. - С. 308-310.

17. Сафонова В.Ю., Сафонова В.А., Жуков А.П. Способ профилактики острой лучевой болезни лабораторных животных: Патент РФ на изобретение // Бюллетень, 2008. № $36 .-5 \mathrm{c}$.

18. Сенникова Ю.А., Гришина Л.В., Гельфгат Е.Л. Отдаленные последствия влияния малых доз радиации на иммунную систему человека // Бюллетень сибирского отделения российской академии медицинских наук. -2005 . - № 2 (116). - C. 59-64.

19. Слюсарева О.А, Воронцова 3.А. Доза-эффекты однократного $\gamma$-облучения и состояние гомеостаза слизистой оболочки тощей кишки в динамике пролонгированности сроков наблюдения // Вестник новых медицинских технологий. - 2010. - Том XVII, № 2. - С. 39-41.

20. Смирнова С.Г., Орлова Н.В., Замулаева И.А. и др. Мониторинг частоты лимфоцитов, мутантных по генам Т-клеточного рецептора, у ликвидаторов последствий аварии на ЧАЭС в отдалённый пострадиационный период // Радиация и риск. - 2012. - Том 21. № 1. - С. 20-29.

21. Узбеков Д.Е., Чайжунусова Н.Ж., Шабдарбаева Д.М., Саякенов Н.Б., Узбекова С.Е., Саимова А.Ж. Состояние перекисного окисления липидов в иммунокомпетентных органах поколений крыс, подвергнутых Сo60 // Наука и Здравоохранение (Специальный выпуск). - Семей, 2014. № $6 .-106$ c. 
22. Хаитов Р.М., Манько В.М. Вклад Александра Александровича Ярилина в развитие современной иммунологии // Иммунология. - 2014. - Том 35, № 4. - С. 172-195.

23. Яськова Е.К., Степаненко В.Ф., Петриев В.М. и др. Оценка поглощенных доз внутреннего облучения лабораторных животных при введении радио-фармпрепаратов, меченных технецием-99m и рением-188 // Радиация и риск (Бюллетень Национального радиационно-эпидемиологического регистра). - 2010. - Том 19, № 4. - С. 50-57.

24. Dainiak N. Hematologic consequences of exposure to ionizing radiation // Exp. Hematol. - 2002. - Vol. 30. - P. 513-528.

25. Denise S. Radiation Therapy Side Effects on the Immune System (19.10.2015), available at: www.livestrong. com/article/263543-radiation-therapy-s..

26. Endo S., Taguchi Y., Imanaka T., Fukutani S., Granovskaya S., Hoshi M. et al. Neutron activation analysis for soils of Hiroshima City and Plaster under roof-tiles of Old Hiroshima House// Revisit the Hiroshima A-bomb with a Database Vol. 2, Hiroshima City 2013, ISBN: 978-4-99059351-3,9-14, 2013.

27. Imanaka T., Yamamoto M., Kawai K., Sakaguchi A., Hoshi M., Chaizhunusova N., Apsalikov K. Reconstruction of local fallout composition and gamma-ray exposure in a village contaminated by the first USSR nuclear test in the Semipalatinsk nuclear test site in Kazakhstan // Radiation and environmental biophysics. - 2010. № 49. - P. 673-684.

28. Jepson J. Hormonal Control of Erythropoiesis during Pregnancy in the Mouse Text / J. Jepson, L. Lowenstein // British Journal of Haematology. - 2008. - Vol. 14, № 6. - P. 18-23.

29. Jones I.M., Galick H., Kato P. et al. Three somatic genetic biomarkers and covariates in radiation-exposed Russian cleanup workers of the Chernobyl nuclear reactor 6-13 years after exposure // Radiat. Res. - 2002. - Vol. 158, № 4. P. 424-442.

30. Khaitov R.M., Mankov M., Yarilin A.A. Intracellular signaling pathways, activating or inhibiting immune system cells. Molecular mechanisms generating activating signalling pathways of phagocytes mediated by $\mathrm{Fc}-$ and $\mathrm{tlR} / /$ Int. Rev. Allergol. clin. Immunol. - 2005. № 11 (3). - P. 79-90.

31. Kouya Honda. Human body influence of the residual radiation which ORNL-TM-4017// Journal of the Japan Statistical Society. - 2012. - Vol. 42, № 1. - P. 103-117.

32. Kusunoki Y, Hayashi T. Long-lasting alterations of the immune system by ionizing radiation exposure: Implications for disease development among atomic bomb survivors// International Journal of Radiation Biology. - 2008. - P. 1-14.

33. Kusunoki Y., Kyoizumi S., Hayashi T., Kubo Y., et al T-cell Immunosenescence and inflammatory Response in Atomic Bomb Survivors // Radiat. Res. - 2010, № 174 (6). - P. 870-876.

34. National Academy of Sciences Committee on the Biological Effects of Ionizing Radiation (BEIR). Report VII. Health effects of exposure to low levels of ionizing radiations: time for reassessment? Washington, DC: National Academy of Sciences. -2005 .
35. Neronova E., Slozina N., Nikiforov A. Chromosome alterations in cleanup workers sampled after the Chernobyl accident // Radiat. Res. - 2003. № 1. - P. 46-51.

36. Orlov M., Stepanenko V., Belukha I., Ohtaki M., Hoshi M. Calculation of contact beta-particle exposure of biological tissue from the residual radionucides in Hiroshima // Health Physics. - 2014. - Vol. 107, № 1. - 44 p.

37. Park H.R., Jo S.K., Paik S.G. Factors effecting the Th2-like immune response after gamma-irradiation: low production of IL-12 heterodimer in antigen-presenting cells and small expression of the IL-12 receptor in T cells // International Journal of Radiation Biology. 81. - 2005. - P. 31-221.

38. Pecaut M.J., Nelson G.A., Gridley D.S. Dose and dose rate effects of whole-body gamma-irradiation: I. Lymphocytes and lymphoid organs. - 2001. - Vol. 15, № 3. - P. 195-208.

39. Preston D.L. Radiation-related health risks at low doses among atomic bomb survivors// 11-th International Congress of the International Radiation Protection Association, Plenary Panel Session 1 (Madrid, Spain, 23-28 May). - 2004. P. $86-178$.

40. Reiner S.L. Development in motion: helper T cells at work. Cell 2007. - 2007. -Vol. 129. - P. 54-57.

41. Reuben J.M., Korbling M., Gao H., Lee B.N. The effect of low dose gamma irradiation on the differentiation and maturation of monocyte derived dendritic cells / J. Gravit // Physiol. 11. - 2004. - P. 39-42.

42. Steinert M. et al. Delayed effects of accidental cutaneous radiation exposure: fifteen years follow-up after the Chernobyl accident / J. Am// Acad. Dermatol. - 2003. - Vol. 49, № 3. - P. 417-423.

43. Surace L., Scheifinger N.A., Gupta A., Van den Broek M. Radiotherapy supports tumor-specific immunity by acute inflammation // OncoImmunology. - 2016. - Vol. 5, № 1. P. 73-77.

44. The 2007 Recommendations of the International Commission on Radiological Protection. ICRP Publication 103 // Annals of the ICRP. - 2007. - Vol. 37, № 2-4. Elsevier, $2007,-332$ p.

45. Tolstykh E.I., Degteva M.O., Peremyslova L.M., et al. Reconstruction of long-lived radionuclide intakes for Techa riverside residents: 137Cs // Health Phys. - 2013. - Vol. 104, № 5. - P. 481-98.

46. United Nations Scientific Committee on the Effects of Atomic Radiation (UNSCEAR). Sources and effects of ionizing radiation. 2000 report to the General Assembly. Vol. 2 Effects (Annex I). New York: United Nation, - 2000.

47. Weitz R. Reconstruction of beta-particle and gamma-ray doses from neutron activated soil at Hiroshima and Nagasaki // Health Physics. - 2014. - Vol. 107, № 1. - 43 p.

48. Zhao H., Guo M., Sun X., Sun W., Hu H., Wei L., Ai H. Effects of recombinant human granulocyte colony-stimulating factor on central and peripheral T lymphocyte reconstitution after sublethal irradiation in mice // Journal of Radiation Research. 2013. № 54. - P. 83-91. 